\title{
Characterization of newly established oral cancer cell lines derived from six squamous cell carcinoma and two mucoepidermoid carcinoma cells
}

\author{
Eun Ju Lee ${ }^{1}$, Jin Kim ${ }^{1}$, \\ Seoung Ae Lee ${ }^{1}$, Eun-Jung Kim ${ }^{1}$, \\ Yong-Chan Chun ${ }^{1}$, Mi Heon Ryu ${ }^{2}$ \\ and Jong-In Yook ${ }^{1,3}$ \\ ${ }^{1}$ Department of Oral Pathology \\ Oral Cancer Research Institute \\ Brain Korea 21 Project for Medical Science \\ Yonsei University, School of Dentistry \\ Seoul 120-752, Korea \\ ${ }^{2}$ Department of Dental Hygiene \\ NamSeoul University \\ Cheon-Ahn 330-707, Korea \\ ${ }^{3}$ Corresponding author: Tel, 82-2-2228-3032; \\ Fax, 82-2-392-2959; E-mail, jiyook@yumc.yonsei.ac.kr
}

Accepted 29 July 2005

Abbreviations: ECM, extracellularmatrix;EGFR, epidermal growth factorreceptor;HPV, humanpap illomavirus;MEC,mucoepidermoid carcinoma;OSC,oralsquamouscellcarcinoma;SCC,squamouscell carcinoma;STR,shorttandemrepeats;YD,YonseiUniversity,School ofDentistry

\begin{abstract}
Since genetic abnormalities of human cancer are greatlygeographicallydependent,culturalanden vironmentalbackgroundsar ethoughttobeclosely relatedtothecarcinogenicprocess.Inthepresent study, eighthumancell lineswere establishedby culturefromuntreatedcarc inomasoftheoralcancer, ofwhichfivewerefromprimaryoralsquamouscell carcinomas (OSC), one from a mucoepidermoid carcinoma (MEC) and one each originating from metastaticOSCandMEC.Allthestudiedtumorlines grewas monolayers, and showed:i) an epithelial origin by the presence of cytokeratin, and ii) tumorigenic potential in nude mice. Western blot analysisrevealedi)overexp ressionofEGFRinsix of the cell lines ii) decreased expression of Ecadherininsixcelllinescomparedtonormalhuman oralmucosa.Amutationalanalysisshowed:point mutationsofp53atexon7,withtransversion,andat exon 8, with transition. These well-characterized humanYDcellinesshould serveasusefultoolsin
\end{abstract}

thestudy ofthemolecu larpathogenesisandbiologicalcharacteristicsofheadandneckcancercells, andinthefuturetestingofnewtherapeuticreagents fororalcancer.

Keywords:carcinoma,mucoepideermoid;cadherins; carcinoma,squamouscell;cellline,tumor;mouthneoplasms;p53;receptor,epidermalgrowthfactor

\section{Introduction}

Therehavebeenmanystudiesontheestablishment of cancer cell lines, they contribute to various basic research on cancer, as well as to diagnostic and therapeutic development. However, the establishment of an oral cancer cell line is especially difficult from the primary site, and only a few successful attemptshavebeen reported(Easty etal., 1981; Hu et al., 1984; Roa etal., 1985; Sacks etal., 1988; Tatke etal., 1995; Ji etal., 2001). Most previously establishedcelllineshavebeenreportedfromlymph node metastaticfoci, or transplanted tumors in nude mice. The reasons for the low success rate of establishing cell lines from primary tumors are considered to be due to bacterial contamination when the tumor tissue was resected and the low cellular activity of primary tumors compared to that of the metastatic tumors. However, cell lines derived from recurrent tumors, or metastasis, appear to be less differentiated, less well organized in culture, and demonstrate a morphological divergence displaying fewer desmosomes and tonofilaments, than cells in primary tumor lines (Easty et al., 1981). For these reasons, cell lines from primary tumors are required for understanding the biological characteristics of oral cancer. In addition, genetic abnormalities of humancanceraregreatlygeographicallydependent, so cultural and environmental backgrounds are thought to be closely related to carcinogenic process. In this report, 8 carcinoma cell lines, derived from six untreated primary, and two metastatic, tumors of the head and neck, were established and characterized, and designated as the YD cell lines. Of these cell lines, two originated from metastatic lymph nodes. The molecular characteristics, including the frequency of 'high-risk' HPV infection and their proliferating activities, degree of differentiation, status of proto-oncogene EGFR, E-cadherin, and 
mutation of tumor suppressor gene p53 were also studied.

\section{Materials and Methods}

\section{Establishment of cell lines}

The surgical specimens were obtained from the operation room suite, and transported to the laboratory in Dulbecco's modified Eagle's medium (DMEM; Gibco BRL, Grand island, NY), supplemented with $10 \%$ fetal calf serum(FBS), $1 \times 10^{-10} \mathrm{M}$ cholera toxin, $0.4 \mathrm{mg} / \mathrm{ml}$ hydrocortisone, $5 \mu \mathrm{g} / \mathrm{ml}$ insulin, $5 \mu \mathrm{g} / \mathrm{ml}$ transferrin, and $2 \times 10^{-11} \mathrm{M}$ triiodothyronine. The cancer tissues obtained from the patients were treated with trypsin, and then the isolated cancer cells were grown with a feeder layer of mitomycin C-treated NIH 3T3 fibroblasts. The cells were fed with a mixture of DMEM and Ham's nutrient mixture F12 (Gibco BRL, Grand island, NY), at a 3:1 ratio, supplemented with $10 \% \mathrm{FBS}, 1 \times 10^{-10} \mathrm{M}$ cholera toxin, $0.4 \mathrm{mg} / \mathrm{ml}$ hydrocortisone, $5 \mu \mathrm{g} / \mathrm{ml}$ insulin, $5 \mu \mathrm{g} / \mathrm{ml}$ transferrin, and $2 \times 10^{-11} \mathrm{M}$ triiodothyronine (T3). The cells were fed in an incubator at $37^{\circ} \mathrm{C}$, with an atmosphere containing $5 \% \mathrm{CO}_{2}$. The characteristics of the patients from whom these cell lines were established are given in Table 1. Histopathology showed that five cell lines were from primary SCC and one from a primary MEC. One each originated from metastatic SCC and MEC.

\section{Growth assay of the human OSC cell lines}

Cells were plated at $1 \times 10^{4}$ cells $/ 200 \mu \mathrm{l}$ in each well of a 96 well plate. Every $24 \mathrm{~h}, 200 \mu$ of the yellow MTT solution $(0.05 \mathrm{mg} / \mathrm{ml}$; Sigma Chemical Co., St. Louis, MO) was added to each well. The plates were covered with aluminum-foil, and then incubated at $37^{\circ} \mathrm{C}$, in $5 \% \mathrm{CO}_{2}$ and $95 \%$ air, for $3 \mathrm{~h}$. After incubation, purple formazan salt crystals were formed. The untransformed MTT that remained in the supernatant was removed by aspiration. The formed formazan crystals were dissolved by adding $150 \mu \mathrm{l}$ of dimethylsulfoxide (DMSO; Sigma Chemical Co., St. Louis, MO). The plates were then placed into an ELISA reader (Benchmark Microplate Reader, BioRad, Herclues, CA), and the optical density of the plates read at $570 \mathrm{~nm}$ to measure the maximal absorbance of the solubilized formazan product. For each time period, the mean optical density value was calculated. After establishing the growth curves, the population doubling times of the established cell lines were estimated from the exponential growth phase.

\section{DNA profiles}

Genomic DNA was extracted using the QIAamp DNA Mini kit (Qiagen, Hilden, Germany) according to the manufacturer's protocols. For DNA-finger printing analysis, DNA was amplified by PCR using short tandem repeats (STR) markers. Eight cell culture samples were genotyped using PowerPlex16 (Promega, Medison, WI). Genotypes of 15 autosomal STRs (D3S1358, TH01, D21S11, D18S51, Penta E, D5S818, D13S317, D7S820, D16S539, CSF1PO, Penta D, vWA, D8S1179, TPOX and FGA) were determined in eight cell culture samples. Additional genotypes of 5 X-STRs (GATA172D05, HPRTB, DXS8377, DXS101, HumARA) and 9 YSTRs (DYS19, DYS385a/b, DYS389-I, DYS389-II, DYS390, DYS391 and DYS393) were determined in YD-10B by PCR (Shin et al., 2004). The PCR products were analyzed by capillary eletrophoresis using an ABI PRISM 310 Genetic Analyzer (Applied Biosystems, Foster City, CA).

\section{In vivo tumorigenicity}

To investigate the in vivo tumorigenicity of the YD cell lines, $3-5 \times 10^{6}$ cells, mixed in DMEM, were injected subcutaneously into 4-6 week old male athymic nude mice (nu/nu; BALB/C), and the tumor formation was examined daily. When the mass had grown more than $1 \mathrm{~cm}$, it was surgically removed, fixed in a $10 \%$ formalin solution, and paraffin-embedded, for histological evaluation.

\section{Flow cytometric DNA measurement}

The cells were washed twice with PBS, resuspended in $500 \mu \mathrm{l}$ of ice-cold ethanol and maintained at $4^{\circ} \mathrm{C}$ for at least $30 \mathrm{~min}$. Prior to analysis, the cells were washed again with ice-cold PBS, resuspended in $500 \mu \mathrm{l}$ of ice-cold PBS and treated with $0.1 \mathrm{mg} / \mathrm{ml}$ RNase A (Sigma Chemical Co., St. Louis, MO) at $37^{\circ} \mathrm{C}$ for $30 \mathrm{~min}$. Propidium iodide (PI; Sigma Chemical Co., St. Louis, MO), at a final concentration of $50 \mu \mathrm{g} / \mathrm{ml}$, was then added to the cell suspensions. After incubation on ice for $30 \mathrm{~min}$, the cells were analyzed on a FACScan flow cytometer (Becton Dickinson, San Jose, CA) equipped with an Argon laser, at $488 \mathrm{~nm}$. The percentages of cells in the G0-G1, S, and G2-M phases were estimated under the assumption of a Gaussian distribution. The multicycle mode FIT 2.0 cell cycle software (version 2.0, Verity Software House Inc., Topsham, ME) was used to calculate the fraction of cells in the G0-G1 (represented by the first peak on the histogram), $S$ (between the first peak and second peak), and G2-M (the second peak) phases. The protocol was repeated in triplicate for each group, and the means 
and standard deviations determined.

\section{Immunohistochemistry}

For immunohistochemical staining, the paraffin-embedded tissues from both surgical specimens and the culture tissues were used. After deparaffinization and rehydration, the endogenous peroxidase was blocked with $3 \% \mathrm{H}_{2} \mathrm{O}_{2}$ in methanol, and the sections incubated with normal horse serum at room temperature. Subsequently, a primary antibody, AE1/3 (DAKO, Glostrup, Denmark) or Vimentin (DAKO, Glostrup, Denmark), was applied overnight at room temperature to detect cytokeratins. Slides were then incubated with biotin-labeled horse anti-mouse/antirabbit IgG (Vector Lab., Burlingame, CA) at room temperature for $30 \mathrm{~min}$. Subsequently, the slides were incubated, with horseradish peroxidase streptavidin, at room temperature for 30 min. 3,3-diaminobenzidine tetrachloride was used for visualization, and slides were counterstained with Meyer's hematoxylin.

\section{Immunofluorescence studies}

Cells were seeded on eight-chambered cover glasses (Nunc Inc., Naperville, IL) at $2 \times 10^{4}$ cells/chamber. Slides were fixed with acetone at $-20^{\circ} \mathrm{C}$ for 10 $\mathrm{min}$, then incubated with primary mouse monoclonal antibodies directed either against vimentin at 1/100 dilution (DAKO, Glostrup, Denmark) or cytokeratin at 1/50 (DAKO, Glostrup, Denmark) or AE1/AE3 (DAKO, Glostrup, Denmark) for $60 \mathrm{~min}$. After washing, Alexa 594 donkey anti-sheep IgG conjugate (Molecular Probes Inc., Eugene, OR) were then added for $60 \mathrm{~min}$ and fixed again with ice-cold methanol for $10 \mathrm{~min}$. All stained cells were stored under FluoroGuard antifade mounting reagent (Bio-Rad, Herclues, CA) and viewed by fluorescence microscopy.

\section{Western blot analysis}

Western blot analyses were performed as previously described (Yook et al., 1998) using anti-p53 antibody (Pab 1801, Oncogene Sciences, Cambridge, MA), anti mouse E-cadherin monoclonal antibody (clone 36, BD Bioscience, San Diego, CA) and anti-EGFR antibody (clone E-30, Biogenex Co, San Ramo, CA) from the cell lysate. All the lanes contained equal amounts of protein, as determined by the Bradford method. After probing with each of the respective antibodies, the membranes were visualized by enhanced chemiluminescence.

\section{Determination of HPV infection}

A polymerase chain reaction (PCR) method was used for the detection of human papillomavirus
(HPV) genotypes using general primer sets (Mork et al., 2001). Two pairs of general primers were selected from the conserved $\mathrm{L} 1$ open reading frame, with the use of these primers in the PCR enabling the detection of the HPV genotypes HPV-1a, -6, -8, $-11,-13,-16,-18,-30,-31,-32$ and -33 . The L1 general primers sequences were as follows: GP5 5' TTTGTTACTGTGGTAGATAC, GP6 5'GAAAAATAAACTGTAAATCA. The viral gene was amplified with DNA extracted from the OSC cell lines, using the L1 general primers. Caski (HPV16), HeLa (HPV18), and HT3 cell lines were used as positive and negative controls, respectively.

\section{Mutation Screening in p53}

DNA was extracted from the harvested culture cells using the phenol-chloroform method. PCR-SSCP analysis was performed to screen for p53 gene mutations in the OSC cell lines. The p53 exons 5-9 were each amplified with 100ng genomic DNA, 20 pmol of each primer, 2 umol dNTP, $10 \mathrm{mM}$ Tris- $\mathrm{HCl}$ ( $\mathrm{pH}$ 8.3), $50 \mathrm{mM} \mathrm{KCl}, 2.0 \mathrm{mM} \mathrm{MgCl}$ and $0.2 \mathrm{U}$ Taq polymerase (Perkin-Elmer, Boston, MA). The conditions used for PCR were: 30 cycles each of, denaturation for 30 seconds at $94^{\circ} \mathrm{C}$, annealing for 30 seconds at $60^{\circ} \mathrm{C}$, and extension for $1 \mathrm{~min}$ at $72^{\circ} \mathrm{C}$, in an automated thermal cycler (Perkin-Elmer, Boston, MA). The p53 primer sequences and PCR fragment sizes were as Table 1. SSCP was performed on $1 \mu \mathrm{l}$ of PCR product diluted with $9 \mu$ loading buffer $(95 \%$ formamide, $0.25 \%$ bromophenol blue, $0.25 \%$ xylencyanol). Samples were denatured at $95^{\circ} \mathrm{C}$ for 5 min and immediately chilled on ice. Generally, $7 \mu \mathrm{l}$ samples were applied to a $20 \%$ polyacrylamide gel and run at 100-150 $\mathrm{V}$ for 3-8 h. For optimal conditions, electrophoresis was done at $4^{\circ}, 14.5^{\circ}$ and $25^{\circ} \mathrm{C}$ using several PCR products in which mutations on each exon were confirmed by sequencing. Then Gels were then stained using the DNA Silver Staining Kit (Bioneer, Korea).

\section{DNA sequencing analysis}

The PCR products were cloned, using the pGEM T-easy vector system (Promega, Madison, WI), and subsequently sequenced using an automated DNA sequencer (Autoassembler 1.0, Perkin Elmer, Boston, MA). The HT3 (codon 245 of exon 7: GGC $\rightarrow$ GTC) and Caski cell lines (wild type p53 gene) were used as positive and negative controls, respectively.

\section{Results}

\section{Establishment of YD cells}

Eight carcinoma cell lines, from surgical specimens 
oforal carcinoma specimens, designated as the YD cell lines, were established, of which 3 were from tongue (YD-8, -10B, and -15) and 2 from lower gingiva (YD-17 and -38). The YD-15M and YD-17M were originated from metastatic lymph nodes and YD-9 from buccal cheek. Histopathologically, all tumors, except two, were classified as SCC. The clinicopathological findings of 6 patients were sum marized in Table 1. Within the first 2 weeks of culture,thetumorcellclustersadheredtothesurfaceof the dish, and gradually formed cell colonies. Once the tumor cells adapted to the in vitro conditions, they proceeded to grow rapidly. When the tumor cells had grown to semiconfluence in the dish, the first subculture was performed by transferring them to $25 \mathrm{~cm}^{2}$ flasks (Nunc). Thereafter, subcultures were performed periodically in a solution of $0.2 \%$ trypsinand $0.1 \%$ ethylenediaminetetraaceticacid.All ofthecell lineshave beenmaintained formorethan 2 yrs, passaged over 100 times, and continue to growinamonolayer(Table2).

\section{DNA profiles}

In order to confirm sample sources and assess the possibilityofsampleswitchingorcontamination, eight cell culture samples were genotyped using PowerPlex16.Genotypesof15autosomalSTRs(D3S 1358, TH01,D21S11,D18S51,PentaE,D5S818,D13S317, D7S820, D16S539, CSF1PO, Penta D, vWA, D8S1179, TPOXandFGA)weredeterminedineight cellculture samples. The genotyping results ofeight cellculturesamplesareuniqueandunrelated(Table 3A). Aadditional genotypes of 5 X-STRs (GATA172D05,HPRTB,DXS8377,DXS101,HumARA) and 9 Y-STRs (DYS19, DYS385a/b, DYS389-I, DYS389II, DYS390, DYS391 and DYS 393) were determined inYD10-Bwhichshowedthreebandedallelepattern in vWA locus. At all $5 \mathrm{X}$-STR and $9 \mathrm{Y}$-STR loci, YD10-B samples displayed only one peak (Table $3 B$ ). These results help exclude the possib ility of crosscontaminationamongthecelllines.

Table 1. Clinical and pathological findings of established oral cancer cell lines.

\begin{tabular}{|c|c|c|c|c|}
\hline Cellline & Age/Sex & Primarysite & Pathologicdiagnosis & Pathologicalnodalstatus \\
\hline YD-8 & $46 / F$ & Tongue & SCC,MD & \\
\hline YD-9 & $56 / M$ & Buccalcheek & SCC,MD & \\
\hline YD-10B & 67/M & Tongue & SCC,MD & \\
\hline $\begin{array}{l}\text { YD-15 } \\
\text { YD-15M }\end{array}$ & 39/M & $\begin{array}{l}\text { Tongue } \\
\text { Lymphnode }\end{array}$ & $\begin{array}{l}\text { MEC,HG } \\
\text { Metastatic }\end{array}$ & 5/17left|2/7,II3/10 \\
\hline $\begin{array}{l}\text { YD-17 } \\
\text { YD-17M }\end{array}$ & $66 / M$ & $\begin{array}{l}\text { Lowergingiva } \\
\text { Lymphnode }\end{array}$ & $\begin{array}{l}\text { SCC,PD } \\
\text { Metastatic }\end{array}$ & $\begin{array}{l}\text { 6/41Right11/10,II5/15, } \\
\text { III0/12,Left0/4 }\end{array}$ \\
\hline YD-38 & 67/M & Lowergingiva & SCC,MD & \\
\hline
\end{tabular}

SCC, squamous cell carcinoma; MEC, mucoepidermoid carcinoma; MD, moderately differentiated; PD, poorly differentiated; HG, high grade

Table 2. Properties of established oral cancer cell lines.

\begin{tabular}{|c|c|c|c|c|c|c|c|c|c|}
\hline \multirow[b]{2}{*}{ Cellline } & \multirow{2}{*}{$\begin{array}{l}\text { Doubling } \\
\text { time }\end{array}$} & \multirow{2}{*}{$\begin{array}{c}\text { Growth } \\
\text { characteristics }\end{array}$} & \multirow{2}{*}{$\begin{array}{c}\text { Prior } \\
\text { chemotherapy }\end{array}$} & \multirow[b]{2}{*}{ Passage } & \multicolumn{4}{|c|}{ Cellcycledistribution } & \multirow[b]{2}{*}{ Tumourigenicity } \\
\hline & & & & & $\begin{array}{c}\text { G0/G1 } \\
(\%)\end{array}$ & $\begin{array}{l}\mathrm{S} \\
(\%)\end{array}$ & $\begin{array}{c}\mathrm{G} 2 / \mathrm{M} \\
(\%)\end{array}$ & DNAindex & \\
\hline YD-8 & 29.3 & Adherent & None & $>100$ & 39.5 & 10.9 & 49.6 & 1.92 & $0 / 5$ \\
\hline YD-9 & 33.4 & Adherent & None & $>142$ & 59.2 & 22.5 & 18.3 & 1.91 & $0 / 5$ \\
\hline YD-10B & 25.3 & Adherent & None & $>137$ & 42.8 & 19.0 & 38.2 & 1.91 & $5 / 5$ \\
\hline $\begin{array}{l}\text { YD-15 } \\
\text { YD-15M }\end{array}$ & $\begin{array}{l}19.8 \\
20.8\end{array}$ & $\begin{array}{l}\text { Adherent } \\
\text { Adherent }\end{array}$ & $\begin{array}{l}\text { None } \\
\text { None }\end{array}$ & $\begin{array}{l}>198 \\
>226\end{array}$ & $\begin{array}{l}47.0 \\
35.5\end{array}$ & $\begin{array}{l}16.6 \\
20.3\end{array}$ & $\begin{array}{l}36.4 \\
44.2\end{array}$ & $\begin{array}{l}1.84 \\
1.91\end{array}$ & $\begin{array}{l}0 / 5 \\
1 / 5\end{array}$ \\
\hline $\begin{array}{l}\text { YD-17 } \\
\text { YD-17M }\end{array}$ & $\begin{array}{l}29.2 \\
19.6\end{array}$ & $\begin{array}{l}\text { Adherent } \\
\text { Adherent }\end{array}$ & $\begin{array}{l}\text { None } \\
\text { None }\end{array}$ & $\begin{array}{l}>196 \\
>100\end{array}$ & $\begin{array}{l}51.9 \\
51.5\end{array}$ & $\begin{array}{l}16.2 \\
12.5\end{array}$ & $\begin{array}{l}31.9 \\
35.9\end{array}$ & $\begin{array}{l}1.91 \\
1.86\end{array}$ & $\begin{array}{l}0 / 5 \\
0 / 5\end{array}$ \\
\hline YD-38 & 21.6 & Adherent & None & $>185$ & 52.1 & 26.3 & 21.6 & 1.92 & $0 / 5$ \\
\hline
\end{tabular}


Table 3A. Observed alleles of the 15 autosomal STR markers in the YD cell lines.

\begin{tabular}{lcccccccc}
\hline Locus & YD-8 & YD-9 & YD-10B & YD-15 & YD-15M & YD-17 & YD-17M & YD-38 \\
\hline D3S1358 & $15-16$ & $15-16$ & $17-17$ & $15-15$ & $15-15$ & $14-15$ & $14-15$ & $16-16$ \\
TH01 & $7-9$ & 6 & $6-9$ & $6-9$ & $6-9$ & $9-3-9.3$ & $9-3-9.3$ & $6-9$ \\
D21S11 & $29-30$ & 30 & $30-32$ & $30-31.2$ & $30-31.2$ & $28-31$ & $28-31$ & $30-31$ \\
D18S51 & $15-16$ & 13 & $14-14$ & $14-14$ & $14-14$ & $14-16$ & $14-16$ & $14-14$ \\
Penta E & $12-15$ & $15-17$ & $5-8$ & $14-19$ & $14-19$ & $5-12$ & $5-12$ & $12-19$ \\
D5S818 & $12-12$ & $10-12$ & $11-13$ & $12-12$ & $12-12$ & $12-12$ & $12-12$ & $14-14$ \\
D13S317 & $8-10$ & 13 & $9-9$ & $11-12$ & $11-12$ & $8-8$ & $8-8$ & $8-8$ \\
D7S820 & $10-13$ & $11-12$ & $11-11$ & $12-13$ & $12-13$ & $10-11$ & $10-11$ & $10-11$ \\
D16S539 & $9-11$ & $12-13$ & $10-11$ & $9-12$ & $9-12$ & $9-12$ & $9-12$ & $12-13$ \\
CSF1PO & $10-10$ & $10-12$ & $12-13$ & $10-12$ & $10-12$ & $10-12$ & $10-12$ & $12-12$ \\
Penta D & $13-13$ & 9 & $8-9$ & $9-9$ & $9-9$ & $9-13$ & $9-13$ & $8-12$ \\
vWA & $14-17$ & $14-19$ & $18-19-20$ & $15-15$ & $15-15$ & $15-16$ & $15-16$ & $14-17$ \\
D8S1179 & $13-16$ & $11-13$ & $11-11$ & $15-15$ & $15-15$ & $13-15$ & $13-15$ & $14-14$ \\
TPOX & $8-11$ & $8-9$ & $8-8$ & $9-9$ & $9-9$ & $8-11$ & $8-11$ & $8-8$ \\
FGA & $24-24$ & 25 & $23-23$ & $23-23$ & $23-23$ & $24-24$ & $24-24$ & $22-25$ \\
\hline
\end{tabular}

\section{Morphologic and biologic characteristics}

Figure 1 shows the photomicrographs of the YD cells. All cells adhered tightly to the flask in a monolayer sheet. The appearance of the YD-8, YD-15, YD-15M, YD-17, YD-17M, and YD-38 cells were polygonal, whereas the YD-9 cells were slightly elongated and the YD-10B cells were round to oval shaped tumor cells. All the YD cell lines grew as monolayers, and their population doubling time ranged from 19.8 to $33.4 \mathrm{~h}$. The average doubling time of the established carcinoma cell lines was $24.9 \mathrm{~h}$, and the YD-15, YD-15M, YD-17M cell lines, derived from metastatic lymph nodes, showed faster doubling times (Table 2). A total of $1 \times 10^{5}$ YD cells, after more than 100th passages, were analyzed by flow cytometry, and the results are summarized in Table 2. All of the cell lines were aneuploid, with a DNA index of around 1.9.

\section{Analysis of epithelial markers and epithelial junction molecules}

To detect cytokeratin expression in the primary and metastatic tumors of the YD cell lines, immunohistochemical staining was performed for $A E 1 / 3$, and cytokeratin was expressed in the cytoplasm of all YD cell lines (Figure 2). In postembryonic cells, cytokeratins are the epithelial counterpart of vimentin; therefore, we also examined the expession of vimentin. Double immunostaining of cells revealed that all of the YD cells expressed only cytokeratin (Figure 2).
Another important characteristic that distinguishes epithelial from mesenchymal cells is the cell junctional complexes formed by homotypic cell adhesion molecules, principally the E-cadherin. Western blot analysis was performed to measure the level of E-cadherin in extract from all of the YD cell lines. E-cadherin was expressed in all YD cells except, but the expression was decreased compare to normal human oral mucosa (Figure 3A).

Table 3B. Observed alleles of the five $X$ - and nine $Y$-linked STR markers in the YD-10B cell line.

\begin{tabular}{lc}
\hline Locus & Observed alleles \\
\hline GATA172 & 10 \\
HPRTB & 12 \\
DXS8377 & 57 \\
DXS101 & 22 \\
HumARA & 23 \\
DYS392 & 11 \\
DYS389I & 13 \\
DYS19 & 15 \\
DYS389II & 29 \\
DYS393 & 13 \\
DYS391 & 10 \\
DYS390 & 24 \\
DYS385a/b & $12-14$ \\
\hline
\end{tabular}


A YD-8

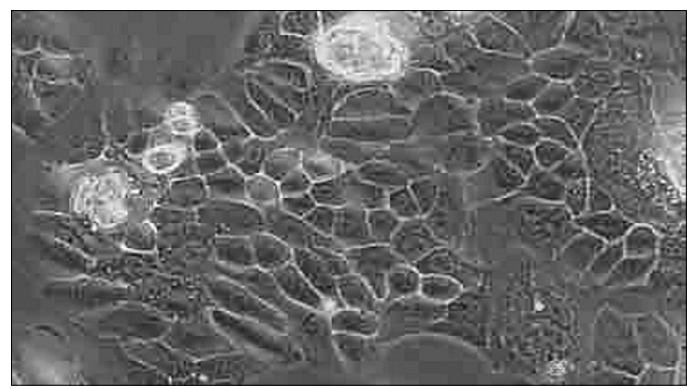

C YD-10

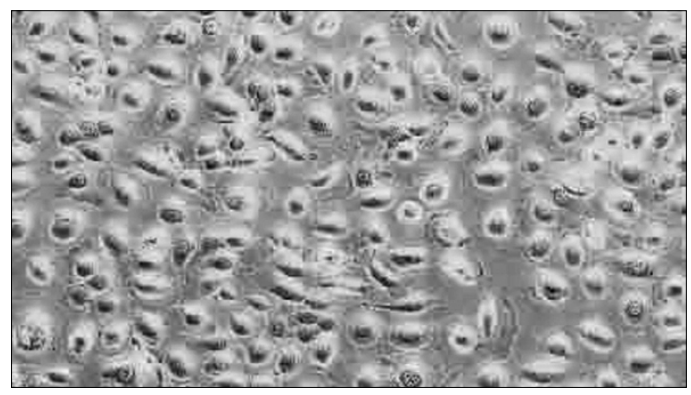

E YD-15M

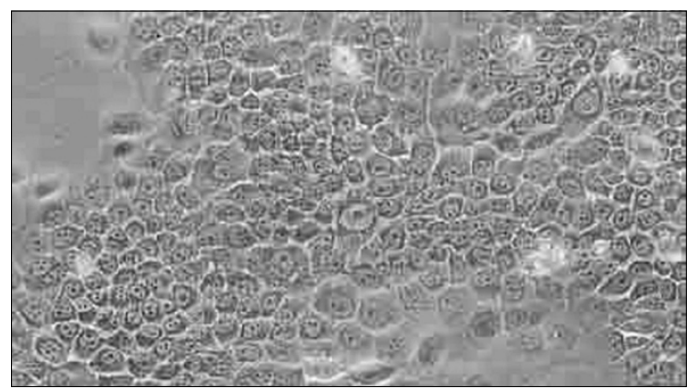

G YD-17M

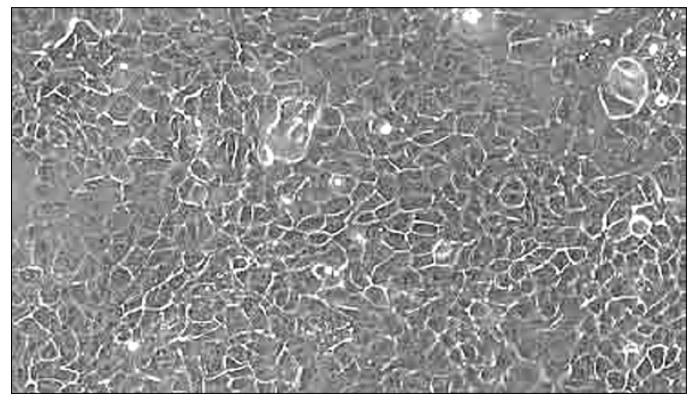

B YD-9

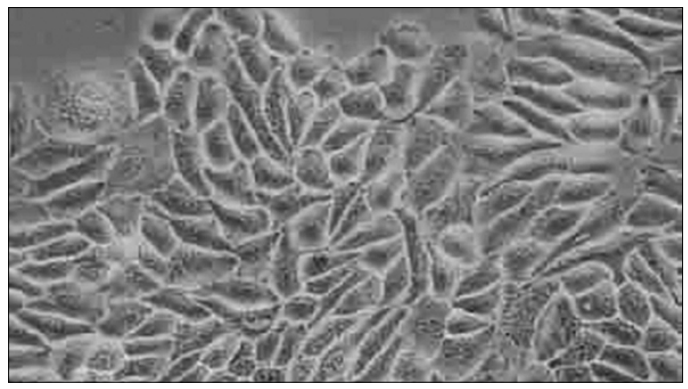

D YD-15

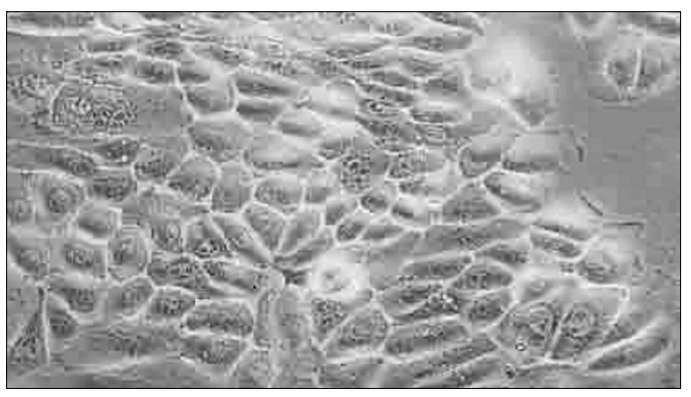

F YD-17

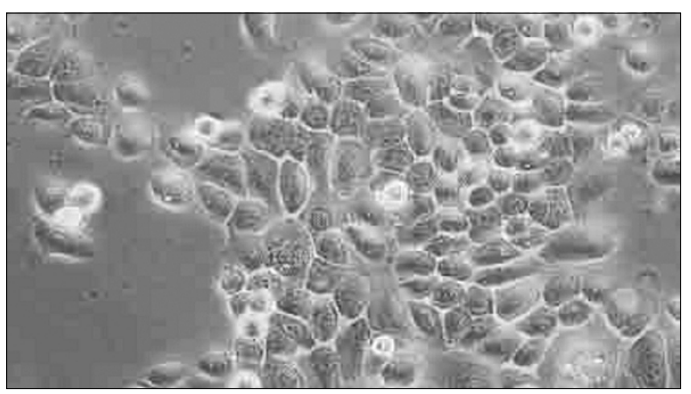

H YD-38

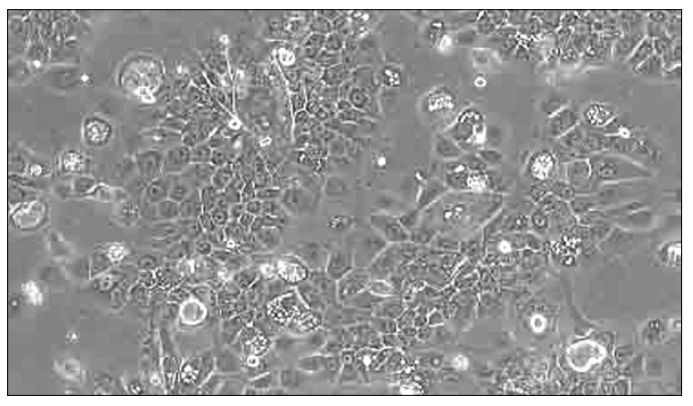

Figure 1. Microscopic features of established oral cancer cell lines. (A) YD-8 showing a sheet of polygonal cells scattered with dyskeratotic cells. (B) YD-9 showing slightly elliptical appearance of tumor cells. (C) YD-10B showing round to oval shaped tumor cells. (D) YD-15 showing relatively round, ovoid or angular shaped tumor cells. (E) YD-15M showing a sheet of oval shaped tumor cells. (F) YD-17 showing a sheet of polygonal cells. (G) YD-17M showing a sheet of polygonal cells similar to YD-17. (H) YD-38 showing a sheet of polygonal cells with irregular border.

Histological observation of transplanted tumors To determine whether the YD cell lines were tumorigenic, $3-5 \times 10^{6}$ cells were subcutaneously injected into nude mice(five mice/cell line). As shown in Table 2 , the YD-10B and $-15 \mathrm{M}$ developed tumors. The incidence of transplantability by subcutaneous ino- 
A YD-8

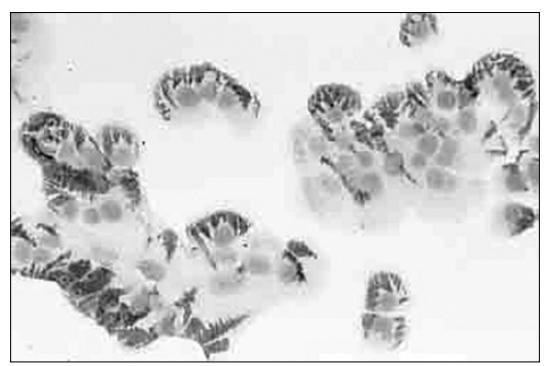

C YD-10B

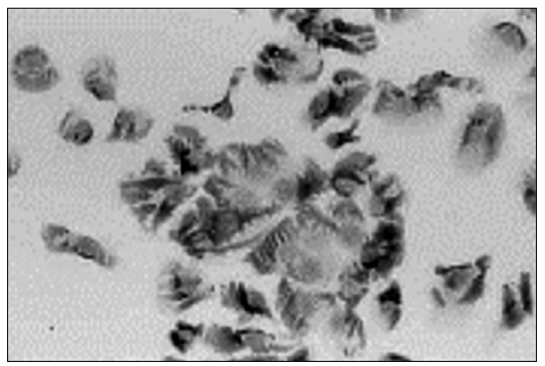

B YD-9

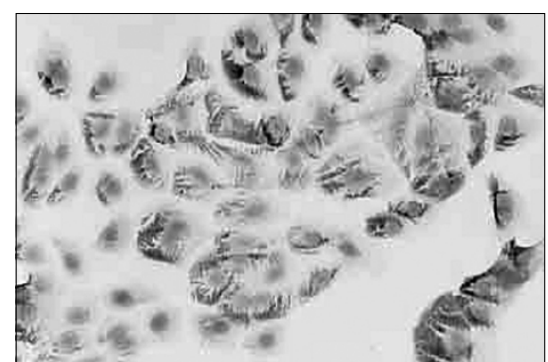

D YD-17M

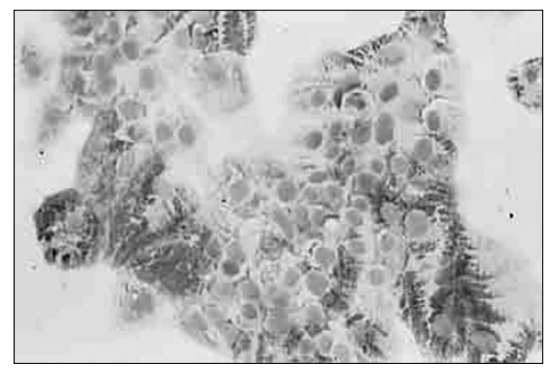

Figure 2. Expression of differentiationmarkersontheestablishedcancercelllines. Immunostainingforcytokeratinsusingthemonoclonalantibody cocktail $A E 1 / A E 3$ was performed. All YD cells showed AE 1/3 immunoreactivity. $A E 1 / 3$ is expressed in the cytoplasms of YD cell lines.

A Immunoblotting for $\mathrm{E}$-cadherin expression

\begin{tabular}{|l|llllllll} 
A431 NK & YD -8 & -9 & $-10 \mathrm{~B}$ & -15 & $-15 \mathrm{M}$ & -17 & $-17 \mathrm{M}$ & -38 \\
\hline & & & & & & & & \\
\hline
\end{tabular}

B Immunoblotting for EGFR expression

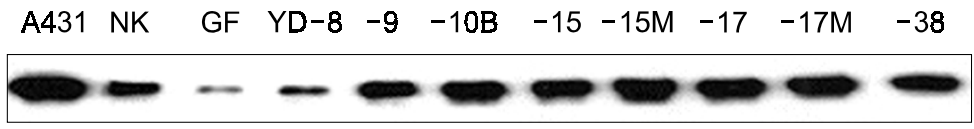

C Immunoblotting for $\mathrm{p} 53$ expression

\begin{tabular}{lllllllll}
$\mathrm{YD}-8$ & -9 & $-10 \mathrm{~B}$ & -15 & $-15 \mathrm{M}$ & -17 & $-17 \mathrm{M}$ & -38 \\
\hline & & & & & & & &
\end{tabular}

D Immunoblotting for $\beta$-actin expression

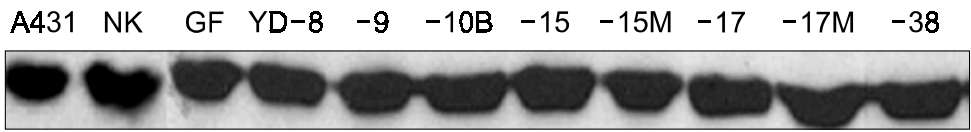

Figure 3. Expression of E-cadherin, EGFR, and $p 53$ intheestablishedoralcancerYDcelllines.(A)E-cadherinexpression of established oral cancercell lines. (B) EGFR expression of established oral cancer cell lines. Most of the cancer cell lines overexpressed EGFRexceptYD-8.(C)p53expressionofestablished oralcancercelllines.(D) $\quad \beta$-actinproteinservedasan internal control. A431, positive control; NK, normal keratinocytes,GF,gingivalfibroblasts.

culation of cancer cells was 1/5 in YD-15M and 5/5 in YD-10B. Transplanted tumors were well circumscribed by surrounding fibrous tissue. No invasive growthwasevident. The centralportion ofthetransplantedtumorsunderwentsevereischemicnecrosis. Transplanted tumorofYD-10B showed well-differentiated SCC and had similar morphology to their respective original tumor of the tongue. However, a transplanted of YD-15M showed a poorly differentiated SCC, this devoid ofmucous cells orglandular
differentiation(Figure4).

\section{Expression of proto-oncogenes EGFR}

Figure3(B)shows the expressionsofEGFRinnewly established YD cell lines, with most overexpressing EGFR, with the exception of the YD-8, compared to normal keratinocytes and gingival fibroblasts. The YD-8celllineharboredaloweramountoftheEGFR expressionthannormalkeratinocytes. 


\section{A Tumor formation In nude mlce}

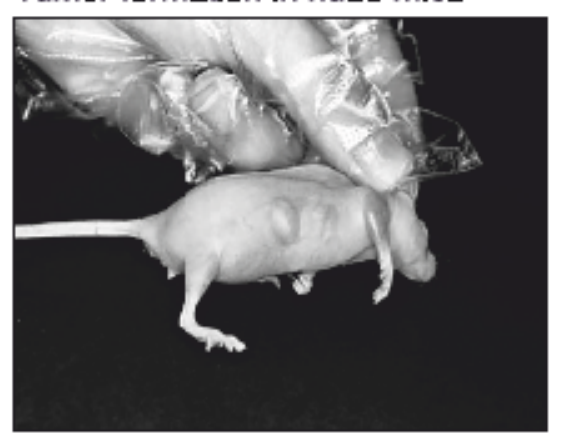

\section{YD-10B}

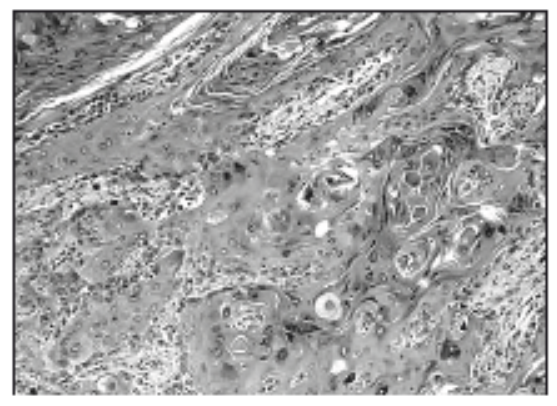

B YD-10B

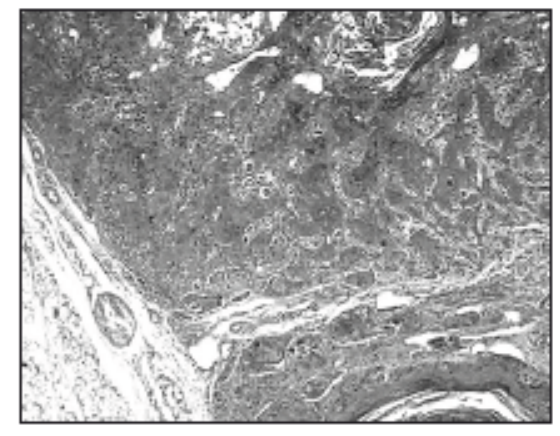

D YD-15M

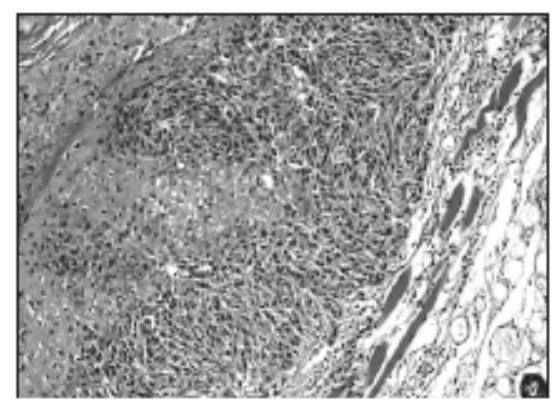

Figure 4. In vivo tumarigenecity in athymic nude mice. (A) Subcutaneous tumor formation in nude mice. The incidence of transplantability by subcutaneous inoculation of cancer cells was $1 / 5$ in YD-15M and 5/5 in YD-10B. (B) Low magnifications (40 $\times$ ) of histopathologic findings of tumor of YD-10B in athymic nude mice showing a well differentiated squamous cell carcinoma. (C) High power of the tumor $(100 \times)$ showing cellular pleomorphism and many mitotic figures. (D) A transplanted of YD$15 \mathrm{M}$ showed a poorly differentiated SCC, this devoid of mucous cells or glandular differentiation.

\section{Mutational analysis in tumor suppressor genes p53}

The presence of mutation of the p53 gene was examined by performing PCR-SSCP and by subsequent DNA sequencing of exons 4-9 of the p53 gene in the YD cell lines (Figure 5). Exon 7 showed point mutation in three cell lines (YD-10B, YD-15, and YD-15M) and exon 8 in one, the YD-8. Both the YD-15 and YD-15M cell lines revealed the same point mutation at codon 258 of exon 7 , that is, the GAA sequence was changed to GCA, which resulted in an amino acid mutation of Glu to Ala. The YD-8 cell line also showed a point mutation at codon 273 of exon 8 , the GGT sequence was changed to CAT, which was changed from Arg to His. The YD-10B cell line showed a frame shift mutation at codon 236 of exon 7 , the TAC sequence was changed to TAA (Table 4). The level of $\mathrm{p} 53$ protein was analyzed by Western blot analysis. p53 protein was detected in the YD-8, YD-9, YD-15, and YD-15M (Figure 3C).

\section{Determination of human papillomavirus (HPV) infection in the human OSC cell lines}

'High-risk' HPVs have been found in OSC, and a large number of studies have examined the relationship between HPV infection and SCC of the oral region. The YD cell lines were examined for the presence of HPV DNA by PCR amplification, and all proved to be free of HPV DNA (Figure 6).

\section{Discussion}

Human cancer cell lines in cultures are widely used in cancer research, where experiments cannot be performed using tissue from in vivo specimens and are important tools in understanding the biology of human cancers. A number of tumor cell lines have been established from human cancers obtained from primary or xenografted tumors (Thomson et al., 1995; Ku et al., 2002). However, the establishment of SCC cell lines is considered to be difficult, and low success rates have been reported. For example, three esophageal carcinoma cell lines were established by one group using 100 specimens ( $\mathrm{Hu}$ et al., 1984), and another group reported the establishment of two head and neck lines from more than 100 specimens (Hauser et al., 1985). In 1981, two teams reported the development of head and neck SCC cell lines. With explants outgrowth techniques, a series of cell lines, designated $\mathrm{HN} 1-\mathrm{HN} 10$, were derived from patients who had received radiotherapy, with or without chemotherapy (Easty et al., 1981). The second group used feeder layer techniques, similar to the methods employed by us, to establish two carcinoma cell lines of the epidermis and four of the tongue (Rheinwald et al., 1981). One patient with a tongue carcinoma had received prior radiation and chemotherapy, but three had not been treated. Using inactivated 3 T 3 mouse cell feeder layers developed these cell lines. Another research group established 
A

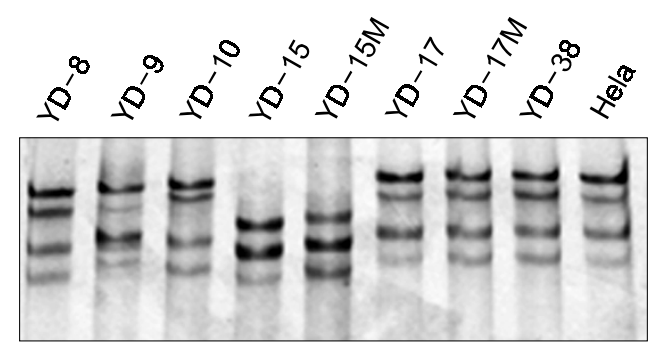

B

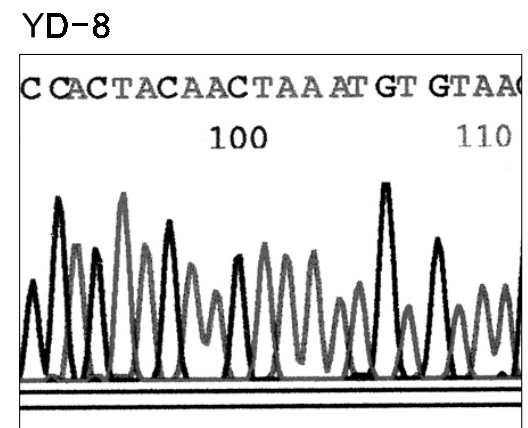

$\operatorname{CGT}(\mathrm{Arg}) \longrightarrow \mathrm{CAT}$ (His)

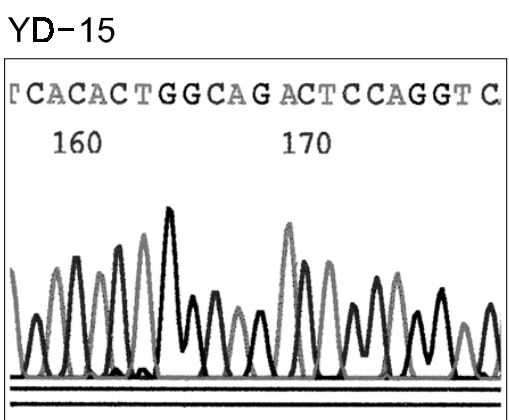

$\mathrm{GAA}(\mathrm{Glu}) \longrightarrow \mathrm{GCA}(\mathrm{Ala})$

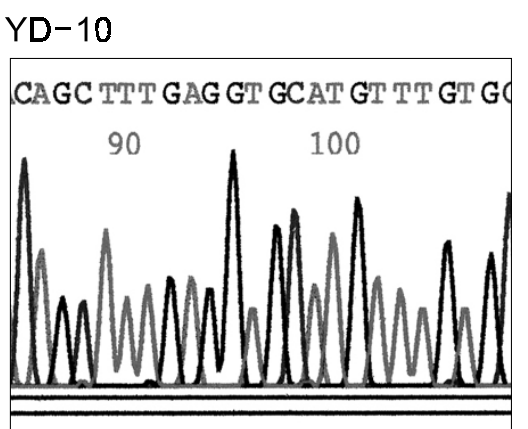

TAC (Tyr) $\longrightarrow$ TAA (Termination)

YD-15M

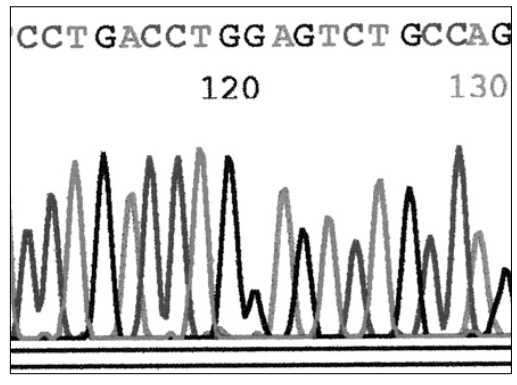

GAA (Glu) $\longrightarrow$ GCA (Ala)
Figure 5. p53 mutations in the established cancer cell lines. (A) PCRSSCP analysis with $20 \%$ acrylamide gel showing band shift of exon 7 in YD-10B, YD-15, and YD-15M. (B) Sequencing results showing point mutations in YD-8, YD-10B, YD-15, and YD-15M.
Table 4. Mutational analysis of p53 in YD cell lines.

\begin{tabular}{|c|c|c|c|c|}
\hline Gene & Cell line & $\begin{array}{l}\text { Mutated codon } \\
\text { (exon number) }\end{array}$ & $\begin{array}{l}\text { Base change } \\
\text { or deletion }\end{array}$ & $\begin{array}{l}\text { Amino acid } \\
\text { change }\end{array}$ \\
\hline \multirow{4}{*}{ P53 } & YD-8 & $273(8)$ & $\mathrm{CGT} \longrightarrow \mathrm{CAT}$ & $\mathrm{Arg} \longrightarrow \mathrm{His}$ \\
\hline & YD-10B & $236(7)$ & $\mathrm{TAC} \rightarrow \mathrm{TAA}$ & Tyr $\longrightarrow$ stop codon \\
\hline & YD-15 & $258(7)$ & $\mathrm{GAA} \longrightarrow \mathrm{GCA}$ & $\mathrm{Glu} \longrightarrow \mathrm{Ala}$ \\
\hline & YD-15M & $258(7)$ & $\mathrm{GAA} \longrightarrow \mathrm{GCA}$ & $\mathrm{Glu} \longrightarrow \mathrm{Ala}$ \\
\hline
\end{tabular}

four new HNSCC cell lines, using outgrowth techniques, on tumors from patients who had received radiotherapy (Rupniak et al., 1985). Thus, while the number of available HNSCC cell lines expands, there are still limited numbers in existence, and even fewer that are useful as models for the development and progression of this important type of tumor. Most of these cell lines were isolated more than $10 \mathrm{yrs}$ ago, however, and have been passaged many times in vitro in uncontrolled growth conditions. Therefore, they could have lost their phenotypic heterogeneity. The use of carcinoma cell lines with a low passage number and newly established cell lines would solve this problem. Tumors are well known to be heterogeneous in a number of their parameters (Dexter et al., 1982). Radiotherapy and chemotherapy, by eliminating sensitive cell populations, may alter a tumor's in vivo progression and cell heterogeneity (Nicolson et al., 1984). Therefore, our interest was in establishing cell lines from tumors from Korean oral cancers, as the development of human cancers, including oral cancers, are known to be closely related to racial and cultural variables, and reference data from different cell lines are required from different 


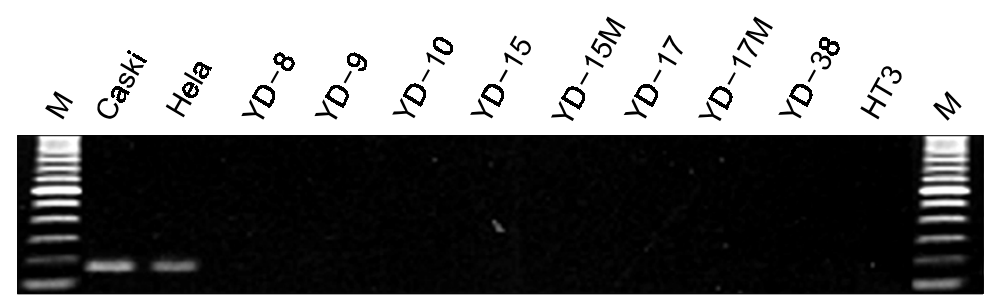

Figure6. DetectionofHPVDNAintheestablishedcancer cellular lines. PCR amplification of tumor cell DNA showing no HPV DNA in establis hed cancer cell lines. Caski andHeLawereusedaspositivecontrolforHPVinfection. ethnic groups for untreated oral cancers as these aremostlikelytorepresenttheoriginal primarytumor. The eight new YD cell lines described here were established from untreated primary tumors. The success rate was at $18 \%$. It is our belief that such cell linesaremorelikelytorepresenttheinitial tumorthan linesderivedfromtherapeuticallytreatedpatients. OSC is the most common malignant neoplasm of theoralmucosa, accountingformorethan $90 \%$ ofall intraoralmalignanttumors. Tobaccoandalcoholuse, viral infections, nutritional deficiency, and dietary habits have all been implicated in the etiology of head and neck cancer (Ahrendt et al., 2000; Balaram etal., 2002). AlthoughtheetiologyofanOSCis unclear, substantial evidence indicates that the activationofproto-oncogenes, andtheinactivation of tumor suppressor genes, underlies the disease development. To understand the molecular mechanismsunderlying the developmentofOSC cellines, the frequency of HPV infection and status of the proto-oncogene (EGFR), and tumor suppressors (p53)wereinvestigated.

The HPV infection is also closely linked to benign and malignant oral lesions (Mork et al., 2001). The involvementoftheHPVinfectioninthedevelopment of oral cancer becomes evident from the frequent detectionof'high-risk'HPVDNAinOSCtissuesand cell lines. Previous studies have reported the presence of HPV types 16 and 18 in oropharyngeal cancers specifically tonsillar cancers. In our study, wefound thatHPV16 presencewasnotsignificantly associated with ourYD cell lines and tissuestested. Previous studies have similarly reported, HPV DNA from Korean fresh tumor tissue subjected to PCR amplification of the L1 or E7 viral region was undetectabe. Ourfindings suggestoral cancerwasstronglyassociatedwithHPV16presenceintheWesternbut notKorean.

In our study, the p53 gene was point mutated in $33 \%$ and frame shift mutated in $11 \%$ of the YD cell lines and all of these mutations occurred in highly conserved regions. The majority of p53 mutations occur in the central conserved part of the protein or 'core domain' (residues 102-292), which is responsible for sequence specificDNA binding. Ingeneral, these mutations are of the missense type and lead to loss of DNA binding, which is believed to be critical for the biological activity ofp53. In our study, codon 258 showed point mutation in two cell lines (YD-15andYD-15M)and codon273inone, the YD8 . The YD-10B cell line showed a frame shift mutation at codon 236 . These results raise questions over the functional significance of p53 gene mutations and this issue was investigated by analyzing p53proteinlevels.Sincethehalf-lifeofwild typep53 protein is several minutes, p53 protein levels in normal cells are relatively very low and generally undetectablebyimmunoblotting. However,abnormal p53 protein can be easily detected by immunoblotting because of the prolongation of its half-life. As shown in Figure 3, the over expression of p53 protein was found in all the p53-mutated YD cell lines, with the exception of one case with a nonsense mutation. However, one of the YD cell lines, not showing the p53 gene mutation, also positively expressed the $\mathrm{p} 53$ protein. There are several possible mechanisms, other than a point mutation, which can result in the over expression of the p53 protein (Yook et al., 1998; Wong et al., 2002). Genetic alternation in another region of the exon, such as the promoter or intron of the p53 gene, could result in a high expression of the wild type p53. However, $90 \%$ of mutations are clustered betweenexons 5 and 8 infourconserved regions of the p53 gene. Another possib ility is the binding of the wild-type p53 protein to other proteins, such as MDM2 or E6 viral oncoprotein, stabilizes and inactivatesasaresultoftheoverexpression(Barenes et al., 1992; Momand et al., 1992; Cho et al., 2002; Seo etal., 2004).TheresultsofPCR-SSCPfollowed by direct DNA sequencing and immunoblotting demonstrated p53 gene mutations associated with abnormal accumulation of p53 protein in OSC cell lines.Sincep53iscloselyrelated tovariousproteins regulating the cellcycle, abnormalp53function may cause accelerated cell proliferation leading to multicentric tumorgenesis and malignant tumor. However, $60 \%$ of multiple and malignant cases showed no mutations of the p53 gene. This suggests that p53 gene mutation is not a necessity for the developmentofmultipleandmalignantOSC. Tounderstandthepossibleroleofproto-oncogenes in the development of the YD cell lines, the expression of EGFR was examined. Several studies 
have demonstrated the over expression of EGFR in primary oral cancers and OSC cell lines (Frank et al., 1991; Satini et al., 1991; Shirasuna et al., 1991). Our results showed the over expression of EGFR in newly established YD cell lines. Interestingly, YD-8 cell line showed much lower expression of EGFR compared to normal oral keratinocyte. Ludes-Mayers et al., (1996) reported that p53 mutations might directly contribute to the gain of some growth promoting functions (gain of function phenotype), rather than represent the mere loss of the wild-type p53 function. Mutant p53 proteins are usually present at high levels in cancer cells, which may lead to the strong and continuous activation of expression in growth related genes, with oncogenic consequences. This observation gives rise to the possibility, that in cancer cells expressing high levels of mutant p53, the mutant protein may transactivate the promoter of the gene expressing human EGFR, resulting in more aggressive growth of these cells. The significance of the wild type p53-mediated transactivation of the EGFR promoter remains unclear. In our study that the YD-8 of p53 mutant cancer cells express high levels of mutant p53 but not EGFR is not likely to occur in p53 mutated cell line. Although our interest was in finding whether the EGFR was amplified dependently or independently of the mutant p53 protein, the details at present are indistinct.

Expression of the cell-cell adhesion molecule Ecadherin correlates with epithelial differentiation and and loss of E-cadherin may induce invasive growth of cancer cells (Batlle et al., 2000; Ackland et al., 2003). Our results showed that all YD cell line expressed E-cadherin. Morphological features of almost all cell lines tested showed polygonal, ovoid or elongated shaped cells representing epithelial differentiated, evidenced by cytokeratin expression.

In summary, eight newly established human OSC cell lines, with the histopathology of their primary tumors, in vitro growth characteristics, epithelial origin, and in vivo tumorigenicity have been reported. In addition, the status of their HPV infection, protooncogene (EGFR), tumor suppressor gene (p53), and E-cadherin are also reported. These eight cell lines will provide new permanent culture models for the study of the pathogenic mechanism, investigation their biological behavior, and to test new therapeutic reagents for oral cancer in the future.

\section{Acknowledgement}

This work was supported by Korea Science and Engineering Foundation 98-0403-07-01-3. We thank Dr. Hwan Young Lee of Department of Forensic Medicine, Yonsei University for professional assistance with DNA profiles analysis.

\section{References}

Ackland ML, Newgreen DF, Fridman M, Waltham MC, Arvanitis A, Minichiello J, Price JT, Thompson EW. Epidermal Growth Factor-Induced Epithelio-Mesenchymal Transition in Human Breast Carcinoma Cells. Lab Inves 2003;83: 435-48

Ahrendt SA, Chow JT, Yang SC, Wu L, Zhang MJ, Jen J, Sidransky D. Alcohol consumption and cigarette smoking increase the frequency of p53 mutations in non-small cell lung cancer. Cancer Res 2000;603:3155-315

Balaram P, Sridhar H, Rajkumar T, Vaccarella S, Herrero R, Nandakumar A, Avichandran RK, Ramdas K, Sankaranarayanan R, Gajalakshmi V, Munoz N, Franceschi S. Oral cancer in Southeren India: the influence of smoking, drinking, paan-chewing and oral hygiene. Int J Cancer 2002;98:440-5

Barenes DM, Hanby AM, Gillett CE. Abnormal expression of wild type p53 protein in normal cells of a cancer family patient. Lancet 1992;340:259-63

Batlle E, Sancho E, Franci C, Dominguez D, Monfar M, Baulida J, Garcia De Herreros A. The transcription factor snail is a repressor of E-cadherin gene expression in epithelial tumour cells. Nat Cell Biol 2000;2:84-9

Blons H, Lauten-Plug P. TP53 and Head and neck neoplasms. Human mutation 2003;21:252-7

Cho CW, Poo H, Cho YS, Cho MC, Lee KA, Lee SJ, Park SN, Kim IK, Jung YK, Choe YK, Yeom YI, Choe IS, Yoon DY. HPV E6 antisense induces apoptosis in CaSki cells via suppression of E6 splicing. Exp Mol Med 2002;34:159-66

Dexter DL, Calabresi P. Intraneoplastic diversity. Biochim Biophys Acta 1982;694:97-112

Easty DM, Easty GC, Carier RL, Monghan P, Butler LJ. Ten human carcinoma cell lines derived from squamouse carcinomas of the head and neck. Br J Cancer 1981;43:772-85

Frank JL, Garb JL, Banson BB, Peterman J, Neifeld JP, Wares JL. Epidermal growth factor receptor expression in squamous cell carcinoma of hypopharynx. Surg Oncol 1993; 2:161-7

Hu C, Hsieh J, Kwang C, Wang P, Wang C, Chen C, Lo SJ, Wuu K, Chang C. Biologic properties of three newly established human oesophageal carcinoma lines. J Natl Cancer Inst 1984;72:577-83

Ji ZW, Oku N, Umeda M, Komori T. Establishment of an oral squamous cell carcinoma cell line (NOS-1) exhibiting amplifiation of the erbB-oncogene and point mutation of p53 tumor suppressor gene: its biological characteristics and animal model of local invasion by orthotopic transplantation of the cell line. Oral Oncology 2001;37:386-92

Keum YS, Kim J, Lee KH, Park KK, Park YJ, Lee JM, Lee SS, Yoon JH, Joo SY, Cha IH, Yook Jl. Induction of apoptosis and caspase-3 activation by chemopreventive[6]paradol and structurally related compounds in KB cells. Cancer Letters 2002;177:41-7

Ku JL, Yoon KA, Kim WH, Jang JY, Suh KS, Kim SW, Park $\mathrm{YH}$, Hwang JH, Yoon YB, Park JG. Establishment and characterization of six human biliary tract cancer cell lines. 


\section{BrJCancer2002;87:187-93}

Ludes-Meyers JH, SublerMA, ShivakumarCV, MunozRM, Jiang P, Bigger JE. Transcripti onal activation of the human epidermal growth factor rec eptor promoter by human $\mathrm{p} 53$. MolCellBiol1996;16:6009-19

Momand J, Zambetti GP, Olson DC, George D, Levine AJ. Themdm-2oncogeneproductformsacomplexwiththep53 proteinandinhibitsp53-mediat edtransactivation.Cell1992; 69:1237-45

MorkJ,lieAK, GlattreE,. HallmansG, JellumE, KoskelaP, Moller B, Pukkala E, Schiller JT, Youngman L, lehtinen M, DillnerJ.Human papillomavirusin fectionasariskfactorfor squamous-cell carcinoma of the head and neck. N Engl J Med2001;344:1125-31

NicolsonGL. Tumorprogression, oncogenesand theevolution of metastatic phenotypic diversity. Clin Exp Metastasis 1984;2:85-105

Rheinwald JG, Beckett MA. Tumorigenic keratinocyte lines requiring anchorage and fibroblas $t$ support cultured from human squamous cell carcinomas. Canser Res 1981;41: 1657-63

RoaAR, Carey TE, PassamaniPP, Greenwood JH, HsuS, SchwartzDR, WolfGT, Huds on JL. DNAcontentofhuman squamous cell carcinoma cell lines; analysis by flowcytometryandchromosomeenumerai on.ArchOtolaryngol1985; 111:565-75

Rupniak HT, povey C, Hill BT. Characteristics of four new human cell lines derived from squamous cell carcinomas of theheadandneck.JNatl CancerInst1985;75:621-35

SacksPG, Parmes SM, Gallic GE, MansouriZ, LichtnerR, Prakash KLS, Pathak S, Parsons DF. Establishment and characterization of two new squamous cell carcinoma cell lines derived from tumours of head and neck. Cancer Res 1988;48:2858-66
Satini J, Formento JL, Francoval M, Dernard F. Characterization, quantitation and potential clinical value of the epidermal growth factor receptor in head and neck squamous cellcacinoma.HeadNeck1991;13:132-9

Seo YR, Jung HJ. The potential roles of p53 tumor suppressor in nucleotide excision repair (NER) and base excisionrepair(BER).ExpMolMed2004;36:505-9

ShinKJ,KwonBK,LeeSS, YooJE,ParkMJ,ChungU,Lee HY, Han GR, Choi JH, Kim JY. Five highly informative Xchromosomal STRs in Koreans. Int J Legal Med 2004;118: $37-40$

Shirasuna K, Hashido Y, Mats uya T. Immunohistochemical localizationofepidermalgrowth factorandepidermalgrowth factor receptor in human or al mucosa and its malignancy. VirchowsArchAPatholAna1991;418:349-53

Tatke RJ, Rajaram N, Damle RN, Balsara B, Bhisey AN, Gangal SG. Establishment of four new squamous cell carcinomacelllinesderivedfrom oralcancer.JCancerRes ClinOncol1990;116:179-86

TomsonAM,ScholmaJ,Dijkuiz enT,WijnakkerAP,vander WerfM, de Jong KM, van Leeuwen MB, Koning JG. Characterisation of human larynx carcinoma cell lines HlaC'79 and $\mathrm{HlaC}$ '82: a common origin but diverged malignancies. ClinExpMatastasis(UK)1995;13:319-27

WongRH,DuCL, WangJD, ChanCC, LuoJCJ, ChengTJ. XRCC1 and CYP2E1 polymorphisms as susceptibility factors of plasma mutant p53 protein and anti-p53 antibody expression in vinyl chloride monomer-exposed polyvinyl chloride workers. Cancer Epi demiology, Biomarkers \& Prevention2002;11:475-82

YookJl,KimJ.Expressionofp21WAF1/CIP1 isunrelatedto p53 tumour suppressor gene status in oral squamous cell carcinoma.EurJCancer1998;34:198-203 